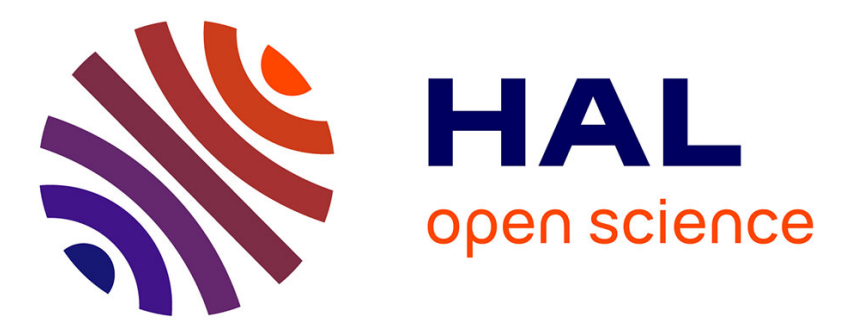

\title{
Determination of electric motor losses and critical temperatures through an inverse approach
}

\author{
Amal Zeaiter, Etienne Videcoq, Matthieu Fénot
}

\section{To cite this version:}

Amal Zeaiter, Etienne Videcoq, Matthieu Fénot. Determination of electric motor losses and critical temperatures through an inverse approach. Electrical Engineering, 2021, 103 (1), pp.621-631. 10.1007/s00202-020-01098-0 . hal-03281064

\section{HAL Id: hal-03281064 https://hal.science/hal-03281064}

Submitted on 7 Jul 2021

HAL is a multi-disciplinary open access archive for the deposit and dissemination of scientific research documents, whether they are published or not. The documents may come from teaching and research institutions in France or abroad, or from public or private research centers.
L'archive ouverte pluridisciplinaire HAL, est destinée au dépôt et à la diffusion de documents scientifiques de niveau recherche, publiés ou non, émanant des établissements d'enseignement et de recherche français ou étrangers, des laboratoires publics ou privés. 


\title{
Determination of Electric Motor Losses and Critical Temperatures through an Inverse Approach
}

\author{
Amal Zeaiter ${ }^{1}$, Etienne Videcoq ${ }^{1}$, and Matthieu Fénot ${ }^{1}$ \\ ${ }^{1}$ Department of Fluid, Thermal, and Combustion Sciences, Pprime Institute UPR 3346, CNRS, \\ ENSMA, University of Poitiers, Poitiers, France \\ Corresponding author: Amal Zeaiter (e-mail: zeaiteramal@gmail.com).
}

\begin{abstract}
In this study, a practical numerical method is proposed to estimate losses of high specific power density electric motors, using few simulated temperature data. In such electric motors, these losses generate high heat fluxes inside the motor components that can be critically sensitive to temperature. Electromagnetic and mechanical friction phenomena are behind the occurring of these thermal dissipations. For both phenomena, losses could be difficult to compute with electrical or mechanical approaches. However, thermal management of electric motors requires a precise knowledge of those losses, in particular for high-performance motors such as those considered in future hybrid planes. To determine electric motor losses in a Permanent Magnet Synchronous Motor (PMSM) in real time, an inverse method using a Lumped Parameter Thermal Model (LPTM) is elaborated. In the first step, the dynamic profile of losses is determined through the inverse method, based on temperature data at easy-access points of the motor. In a second step, the identified losses are used to find temperatures at critical non-accessible hot spot points of the motor through forward LPTM. The method is applied for three useful cases, from the simplest case scenario, where only one type of losses has to be identified, to the most complicated case where all losses are simultaneously estimated. A global strategy for the choice of the number of future time steps used for regularization of the ill-posed problem is also proposed. Results show that this method enables adequate real-time supervision of the critical motor temperatures, mainly rotor and winding core.
\end{abstract}

Keywords: Electrical machines, Future time steps, Losses, Lumped Parameter Model, Thermal behavior, Regularization

\section{INTRODUCTION}

Nowadays, with the rising interest of electrification in the transportation sector, the study and conception of very high-specific power density electric motors is essential. Indeed, weight and volume are known to be classical constraints for electrified vehicles. Moreover, the recent use of electric motors for the propulsion of the new generation of ground and air vehicles requires the development of series of more efficient and higher performance electric motors [1]. This driving trend already exists in the automotive field for electric and hybrid-electric vehicles [2]. Recently, propulsion electrification is emerging into air vehicles design development. Numerous projects [3]-[6] are being conducted aiming to develop electrically propelled aircrafts and are targeting higher values of specific power density in electric motors. In general, these projects focus on hybrid aircrafts in which electric motors, 
coupled to fans, would propel the plane, and the turbo-reactor will be mainly used as a turbine for electricity generation. The increase of specific power density of electric motors could be limited by electrical

\begin{tabular}{|c|c|c|c|}
\hline \multicolumn{4}{|c|}{ Nomenclature } \\
\hline$A(N, N)$ & state matrix & \multicolumn{2}{|c|}{ Greek symbols } \\
\hline$B_{c}(N)$ & command vector relative to environment & $\Gamma$ & system boundary \\
\hline$B_{P}\left(N, n_{p}\right)$ & command matrix relative to heat sources & $\Delta t$ & time step, $\mathrm{s}$ \\
\hline$C_{p}$ & specific heat, $\mathrm{J} \cdot \mathrm{kg}^{-1} \cdot \mathrm{K}^{-1}$ & $\rho$ & density, kg. $\mathrm{m}^{-3}$ \\
\hline$C\left(n_{q}, N\right)$ & output matrix & $\sigma_{U}$ & Mean quadratic error for $U, \mathrm{~W}$ \\
\hline$h$ & $\begin{array}{l}\text { convective exchange coefficient, } \\
\mathrm{W} \cdot \mathrm{m}^{-2} \cdot \mathrm{K}^{-1}\end{array}$ & $\sigma_{Y}$ & Mean quadratic error for $Y,{ }^{\circ} \mathrm{C}$ \\
\hline$I$ & identity matrix & $\chi$ & characteristic space function \\
\hline$k$ & thermal conductivity, $\mathrm{W} \cdot \mathrm{m}^{-1} \cdot \mathrm{K}^{-1}$ & $\Omega$ & system domain \\
\hline$N$ & number of nodes & & \\
\hline$n f$ & $\begin{array}{l}\text { number of future times for specification } \\
\text { function }\end{array}$ & & \\
\hline$n_{p}$ & number of heat sources & Subscripts & \\
\hline$n_{q}$ & number of outputs & ext & Exterior \\
\hline$n t$ & number of time steps & $k$ & time index \\
\hline$P$ & heat source vector, $\mathrm{W}$ & & \\
\hline$U$ & vector of unknown heat sources & & \\
\hline$V$ & vector of known inputs & \multicolumn{2}{|l|}{ Superscripts } \\
\hline vol & volume, $\mathrm{m}^{3}$ & $*$ & noisy temperature \\
\hline$Y\left(n_{q}\right)$ & output vector & $\wedge$ & estimated value \\
\hline & & $T$ & transposition sign \\
\hline & & -1 & inverse of a matrix \\
\hline \multicolumn{4}{|c|}{ Abbreviations } \\
\hline FTS & Future Time Steps & & \\
\hline LPTM & Lumped Parameter Thermal Model & & \\
\hline PMSM & $\begin{array}{lll}\text { Permanent } & \text { Magnet } & \text { Synchronous } \\
\text { Machine } & & \\
\end{array}$ & & \\
\hline SM & Surface Mounted & & \\
\hline
\end{tabular}


and thermal constraints. The multiple electrical limits and the approaches allowing an increase of the motors specific power density are not discussed here, since the related issues are not the main purpose of the paper and are associated to loadability concepts. The interested reader may refer to [7] for further comprehension of these issues.

Thermal limits in electric motors, majorly related to maximum temperature allowed in electric motors windings depending on the insulation thermal class, are at least of the same order of challenge - if not more - than the electrical limits [8-9]. Excessive temperature increase may irreversibly demagnetize magnets [10] or could lead to shortening motor lifetime due to overheated electric insulation material [11]. The temperature increase in electric machines results from electromagnetic and mechanical losses, generating heat in motor components. Generally, these losses are empirically estimated. Besides being hardly evaluated with analytical and some computational methods, it is believed that even with a motor prototype, the process of determination of the resulting losses and distinguishing their types or origins is quite complicated. Generally, such information can be barely obtained with long iterative methods.

Our study focuses on a Permanent Magnet Synchronous Machine (PMSM). In such machines, the temperatures are very sensitive to losses, specifically at hot spot zones. A possible solution to identify electric motor losses is to measure temperature inside the motor and then apply an inverse method. Such methods require a thermal model with quick solving process. Thus, a thermal nodal network could be a good choice as it is commonly used to carry out numerical simulations in the design process of high-performance electric machines.

Being mathematically ill-posed, the solution of the inverse problem may be unstable and not unique. Hence, several regularization techniques have been developed to ensure stable solutions [12]. Examples of inverse problems for electric machines can be found in the literature with different objectives: geometric, thermal or magnetic parameter estimation, loss mapping, source strength determination from temperature measurements. In [13], the authors propose an inverse problem in order to identify a set of 9 design parameters (geometry, magnetic parameters) for a permanent magnet brushless motor. The results show that the density of the magnetic flux in the air gap is increased, as well as the motor efficiency. Moreover, an inverse method for the identification of heat convection coefficients on coil end-windings from experimental data is presented by [14]. An interesting algorithm is developed and described for this nonlinear inverse heat conduction problem using a lumped parameter model. In [15], a low-order model is built in a first stage to estimate a set of thermal parameters. In a second stage, this model is used to identify thermal losses in the stator of an axial flux PM machine. In [16], the power loss density is estimated using a 2D finite-element thermal model associated to a conjugate gradient method from noisy temperature measurements. A prediction of the strength of the heat source field in an induction motor is also carried out in [17] using a steady state thermal model. Another example of reconstruction of thermal field sources can be found in [18]. The aim is to estimate a 3D source distribution using infrared data. The least square method is used in order to solve the inverse problem.

Concerning now the on-line identification of electromagnetic losses, a recursive parameter estimation method is implemented in [19]. Furthermore, a 3D inverse heat conduction problem is presented by [20] to estimate the timedependent internal heat flux generated in rotor and stator for high speed electric motor.

This article deals with the temperature prediction in the electric machines at low accessibility locations through the identification of the heat sources and using an inverse technique. The originality of our numerical study lies in the fact that a low order lumped parameter thermal model that requires a very low computation time is used first to identify the unknown heat sources through an inverse procedure, and secondly to compute the temperature field in the electric machine at each time step in real time. The technique used to solve the mathematically ill-posed problem relies on Beck's contribution [21], [22], which takes into account the lagging and damping effects due to the 
diffusion process by using a sequential method associated to a function specification procedure. This technique acts as a regularization procedure, as it will be shown in this study.

After presenting the electric machine and associated heat transfer modeling, the inverse method applied to identify the heat sources dissipated inside the motor is detailed. Finally, results of parametric studies and corresponding analysis are presented.

\section{THERMAL MODEL}

\section{A. DESCRIPTION OF THE ELECTRIC MOTOR}

The electric motor illustrated in Fig. 1 is a Surface Mounted-Permanent Magnets Synchronous Motor (SM-PMSM) used for hybrid electric aircraft propulsion with specifications found in [23-24]. It is a high efficiency electric motor (more than 96\%) and maximum losses resulting in thermal sources are around $16 \mathrm{~kW}$. These losses are divided into winding Joule losses, Iron losses and mechanical losses.

Geometrically, the motor consists in two parts: the rotor (rotating in the center) and the stator around it.

As shown in Fig. 1, the rotor consists of a shaft (brown) supported by two bearings (grey), surrounded by the rotor lamination (yellow) and the permanent magnets (orange). In the studied motor, the considered heat sources are due to mechanical losses and electric losses. Mechanical losses are mainly due to friction inside the bearings $\left(P_{\text {Bearings }}\right)$, and to aerodynamic heating resulting from very high velocity gradient in the air gap between the rotor and the stator $\left(P_{\text {Airgap }}\right)$ and near the rotor end-caps (lateral surfaces of the rotor) termed $P_{\text {Rotor }}$.

The stator consists of the stator laminations (purple) and the winding (green) whose biggest part is embedded in the stator slots and the remaining part are the end-windings at the extremities of the stator, which are the complex parts in the cavities from geometrical and thermal viewpoints. Windings are heterogeneous elements made up of two types of materials: copper conductors and electric (and thermal) insulation material. The iron losses $\left(P_{\text {Iron }}\right)$ and Joule losses $\left(P_{\text {Joule }}\right)$ are thermal sources distributed in the stator laminations and winding respectively rising from the resistivity of copper in winding conductors. Iron losses are produced by magnetic effects (hysteresis and Foucault's current) and the Joule losses in windings are due to Joule effect.

It is assumed in this study that the thermo-physical properties are temperature independent.

The motor cooling system in this case is a combination of a stator water-jacket with water-glycol flowing around the stator, and a water-glycol axial flow at the center of the shaft for rotor cooling. Both types of liquid cooling are being used in electric motors for vehicular applications (examples can be found in [25]). After flowing through the motor, the water-glycol is cooled with a simple heat exchanger: a channel in contact with ambient air through a flat plate. Moreover, high conductivity resin potting of end-windings is used to increase the heat transfer in those critical regions (due to their high Joule losses). This technique is investigated in [26-27]. 


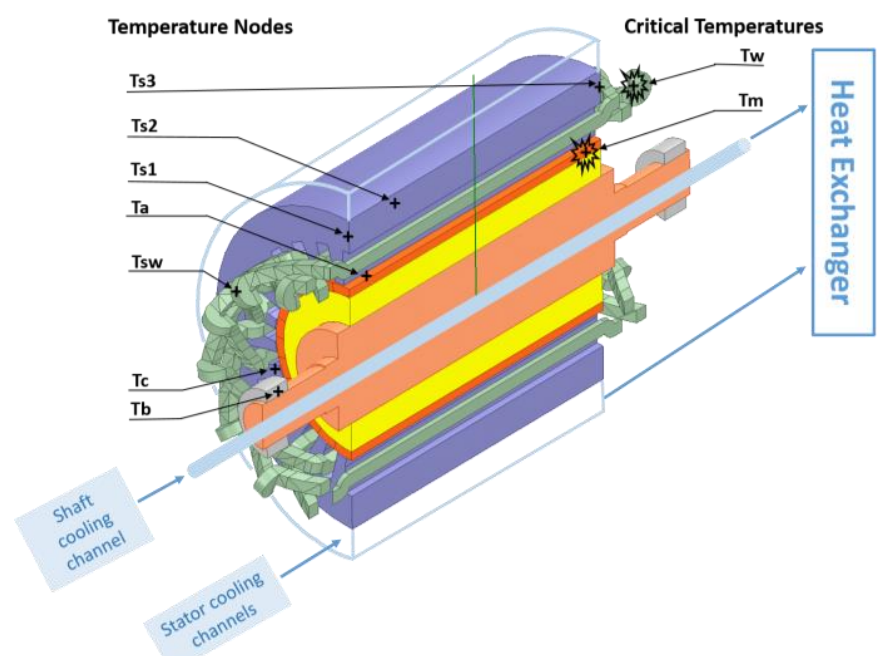

FIGURE 1. SM-PMSM schematic section with specific temperatures' locations.

These techniques have dynamic impact on motor temperatures and thus influence the extraction of the generated heat resulting from the losses. They must be taken into account in any proposed model of the motors.

\section{B. HEAT TRANSFER EQUATIONS AND MODELING}

Temperature distribution within the motor is determined from solving the heat equation associated with initial and boundary conditions. The equation governing heat diffusion and convection in the domain $\Omega$ is written as:

$$
\begin{gathered}
\rho(M) C_{p}(M)\left[\frac{\partial T(M, t)}{\partial t}+\overrightarrow{\mathrm{V}}(M) \cdot \vec{\nabla} T(M, t)\right]= \\
\vec{\nabla} \cdot(k(M) \vec{\nabla} T(M, t))+\sum_{j=1}^{n_{P}}\left[\frac{P_{j}(t)}{V o l_{j}} \chi_{j}(M)\right] \quad \forall M \in \Omega
\end{gathered}
$$

Where $T(M, t)$ is the temperature at a point $M$ in the domain and $\overrightarrow{\mathrm{v}}(M)$ is the velocity field, $\rho$ the density, $C_{p}$ the specific heat and $k$ the thermal conductivity. $P_{j}$ is the time varying strength of the $j^{\text {th }}$ volumetric heat source and $V_{o l} l_{j}$ the corresponding volume. The characteristic function $\chi_{j}(M)$ is equal to 1 if $M$ is located in source $j$, else $\chi_{j}(M)=0$.

Heat exchanges between the motor and its environment are modeled through a global heat transfer coefficient $h$. Boundary conditions hence are written as follows:

$$
k(M) \vec{\nabla} T(M, t) \cdot \vec{n}=h\left(T_{e x t}(t)-T(M, t)\right) \quad \forall M \in \Gamma
$$

Moreover, the initial condition is:

$$
T(M, 0)=T_{\text {init }} \quad \forall M \in \Omega
$$

If the velocity field is not known in a particular region of domain $\Omega$, the transport term in (1) may be modeled by a convective heat transfer as in (2). Then a convective coefficient $h$ has to be evaluated from Nusselt correlations. Besides, the fluid temperature $T_{\text {ext }}$ is required. 


\section{STATE SPACE REPRESENTATION}

As analytical solutions for this 2D axisymmetric transient problem are not available, a Lumped Parameter Thermal Model (LPTM) is used to simulate motor thermal behavior according to (1)-(3). It consists in dividing the studied system into $N$ discrete volumes, which are connected together by thermal conductances. For brevity reasons, details of the network are not given in this paper but can be found in [28]. It leads to a system of ordinary differential equations with a low number of parameters. In our study, $N=58$. This set of equations can be written as:

$$
\dot{T}(t)=A T(t)+B_{c} T_{e x t}(t)+B_{P} P(t)
$$

Where $T(t)$ (dimension $N$ ) is the vector of temperatures, function of time $t$, at the $N$ discretization nodes, $\dot{T}(t)$ its derivative with respect to time $t$. Matrix $A$ (dimension $N, N$ ) is the state matrix which connects temperatures at discretization nodes and contains diffusion and transport terms, as well as terms related to convective boundary conditions. The vector $B_{c}$ is associated with these latter conditions and links corresponding nodes to environment nodes. Matrix $B_{p}$ (dimension $N, n_{p}$ ) links discretization nodes to the internal heat sources gathered in vector function $P(t)=\left[P_{\text {Joule }} P_{\text {Iron }} P_{\text {Rotor }} P_{\text {Airgap }} P_{\text {Bearings }}\right]^{T}$ (dimension $n_{p}$ ).

In what follows, let us separate vector $P$ into two sets: unknown heat sources included in $U$ (dimension $n_{U}$ ) and known heat sources included in $K$ (dimension $\left(n_{p}-n_{U}\right)$. The command matrix $B_{p}$ is then also split into two matrices $B_{p}=\left[B_{K} B_{U}\right]$ Defining the vector $V=B_{c} T_{e x t}+B_{K} K$, the state space representation takes the following form:

$$
\left\{\begin{array}{l}
\dot{T}(t)=A T(t)+V(t)+B_{U} U(t) \\
Y(t)=C T(t)
\end{array}\right.
$$

Where an observation matrix $C$ (dimension $n_{q}, N$ ) allows to select $n_{q}$ temperatures in the whole temperature field $T(t)$ and to store them in vector function $Y(t)$.

In this purely numerical study, a maximum of 9 temperature locations will be used as outputs. These temperatures are depicted in Fig. 1, and are located in the stator lamination (Ts1, Ts2 and Ts3), in the end-winding (Tw) at the surface of the end-winding (Tsw), on the surface of the stator in the airgap (Ta), in the cavity between the rotor endcap and the frame (Tc), in the bearings (Tb), and in the magnets (Tm). These locations have been chosen given the heat sources but also considering plausible experimental measurement system positions. Temperature in the static part of the motor could be obtained using thermocouples (Ts1, Ts2, Ts3, Tsw, Ta, Tb and Tc). The rotor flange temperature could be obtained by infrared measurement. Tm and Tw are the critical temperatures difficult to obtain experimentally due to their locations, i.e. Tw inside the end-windings is confined and thought to be the hottest point and $\mathrm{Tm}$ requires a slip ring due to the rotating rotor.

\section{INVERSE PROBLEM SOLUTION}

The form of heat transfer model, developed in subsection II.C, is convenient to be used now in the inverse procedure. The inverse problem aims at finding an estimation $\widehat{U}$ of the input vector $U$ from measured temperatures $Y^{*}$. Note that, in this study, real temperature measurements are not available. The temperatures included in vector $Y^{*}$ derive from the direct problem with known heat sources. In order to simulate measurement errors, each temperature is altered with an additive Gaussian error, whose standard deviation is given by $\sigma$.

Subsequently, in order to have simplified and clear annotations, we will write $U_{k}$ for $U\left(t_{k}\right), T_{k}$ for $T\left(t_{k}\right), Y_{k}$ for $Y\left(t_{k}\right)$.

A sequential estimation method is adopted. Having the vector of noisy temperatures $Y_{k+1}^{*}$, and an estimated $\widehat{U}_{k}$ of $U_{k}$, an estimation of $\widehat{U}_{k+1}$ is then computed.

Using an Euler implicit scheme and $\Delta t$ being the time step, (5a) becomes: 


$$
\dot{T}=\frac{T_{k+1}-T_{k}}{\Delta t}=A T_{k+1}+V_{k+1}+B_{U} U_{k+1}
$$

Then:

$$
T_{k+1}=(I-A \Delta t)^{-1}\left[T_{k}+\Delta t V_{k+1}+\Delta t B_{U} U_{k+1}\right]
$$

Hence, according to (5b):

$$
Y_{k+1}=C(I-A \Delta t)^{-1}\left[T_{k}+\Delta t V_{k+1}+\Delta t B_{U} U_{k+1}\right]
$$

Due to the lagging and damping effects of heat diffusion and convection, a variation of heat source strength does not immediately affect the sensors. In order to take into account these effects, Future Time Steps (FTS) [29]-[32] are used. It means that output data at further times $t_{k+2}, t_{k+3}, \ldots$ are used to correctly estimate $\widehat{U}_{k+1}$.

If $n f$ is the number of FTS, then for $1 \leq f \leq n f,(8)$ is written for $k+1+f$ instead of $k+1$. A temporary approximation of $U_{k+1+f}$ is therefore needed to look for $\widehat{U}_{k+1}$. In this study, a constant value is chosen:

$$
U_{k+1+f}=U_{k+1} \text { for } 1 \leq f \leq n f
$$

Hence, a global matrix formulation is obtained as in (10):

$$
\mathrm{Y}_{k+1}^{*}=\mathrm{S} U_{k+1}+\mathrm{D}_{k}
$$

With:

$$
\left.\begin{array}{c}
\mathrm{Y}_{k+1}^{*}=\left[\begin{array}{c}
Y_{k+1}^{*} \\
Y_{k+2}^{*} \\
\vdots \\
Y_{k+1+f}^{*} \\
\vdots \\
Y_{k+1+n f}^{*}
\end{array}\right] \\
\mathbf{S}=\left[\begin{array}{c}
C(I-A \Delta t)^{-1} B_{U} \Delta t \\
C\left[(I-A \Delta t)^{-1}+(I-A \Delta t)^{-2}\right] B_{U} \Delta t \\
\vdots \\
C\left[\sum_{j=1}^{f+1}(I-A \Delta t)^{-j}\right. \\
\vdots
\end{array}\right] B_{U} \Delta t \\
C\left[\sum_{j=1}^{n f+1}(I-A \Delta t)^{-j}\right] B_{U} \Delta t
\end{array}\right]
$$

And: 


$$
\mathrm{D}_{k}=\left[\begin{array}{c}
C(I-A \Delta t)^{-1}\left[T_{k}+V_{k+1} \Delta t\right] \\
\vdots(I-A \Delta t)^{-(f+1)}\left[T_{k}+V_{k+1} \Delta t\right]+C\left[\sum_{j=1}^{f}(I-A \Delta t)^{-j}\right] V_{k+2+f-j} \Delta t \\
\vdots \\
C(I-A \Delta t)^{-(n f+1)}\left[T_{k}+V_{k+1} \Delta t\right]+C\left[\sum_{j=1}^{n f}(I-A \Delta t)^{-j}\right] V_{k+2+n f-j} \Delta t
\end{array}\right]
$$

The size of vector $Y^{*}$ is $(n f+1) \times n_{q}$ and matrix $S$ is of size $\left((n f+1) \times n_{q}, n_{U}\right)$. The objective is to identify the pseudosolution $\widehat{U}_{k+1}$ of the inverse problem, such that $Y^{*} Y \approx 0$, where $Y$ is the temperature vector computed by LPTM. As matrix $S$ is not square due to the addition of future time steps, the least square method is used to solve (10) and leads to the sequential solution:

$$
\widehat{U}_{k+1}=\left(\mathrm{S}^{T} \mathrm{~S}\right)^{-1} \mathrm{~S}^{T}\left(\mathrm{Y}_{k+1}^{*}-\mathrm{D}_{k}\right)
$$

In order to evaluate the accuracy of the estimations for the different studied cases, a mean quadratic discrepancy between exact heat sources (vector $U^{\text {exact }}$ ) and estimated ones (vector $\widehat{U}$ ) is defined as follows:

$$
\sigma_{U}=\left[\frac{1}{n_{U} \times(n t-n f)} \sum_{i=1}^{n_{U}} \sum_{k=1}^{n t-n f}\left(\widehat{U}_{i, k}-U_{i, k}^{\text {exact }}\right)^{2}\right]^{1 / 2}
$$

Where $n t$ is the number of time steps in the inverse problem. It is worth to remind that, in a practical application, this quantity is not reachable.

In a similar way, for each output $Y_{i}$, a mean quadratic error between measured temperatures (or artificially noisy temperatures) and those computed with the estimated set of heat sources strengths, is defined as follows:

$$
\sigma_{Y_{i}}=\left[\frac{1}{(n t-n f)} \sum_{k=1}^{n t-n f}\left(\hat{Y}_{i, k}-Y_{i, k+1}^{*}\right)^{2}\right]^{1 / 2}
$$

When the unknown heat sources $\widehat{U}_{k+1}$ are identified, they will be used as inputs in the direct problem in order to predict temperature in inaccessible parts of the motor, for example critical temperatures Tcrit in windings or magnets. The complete procedure is illustrated in the block diagram of Fig. 2. 


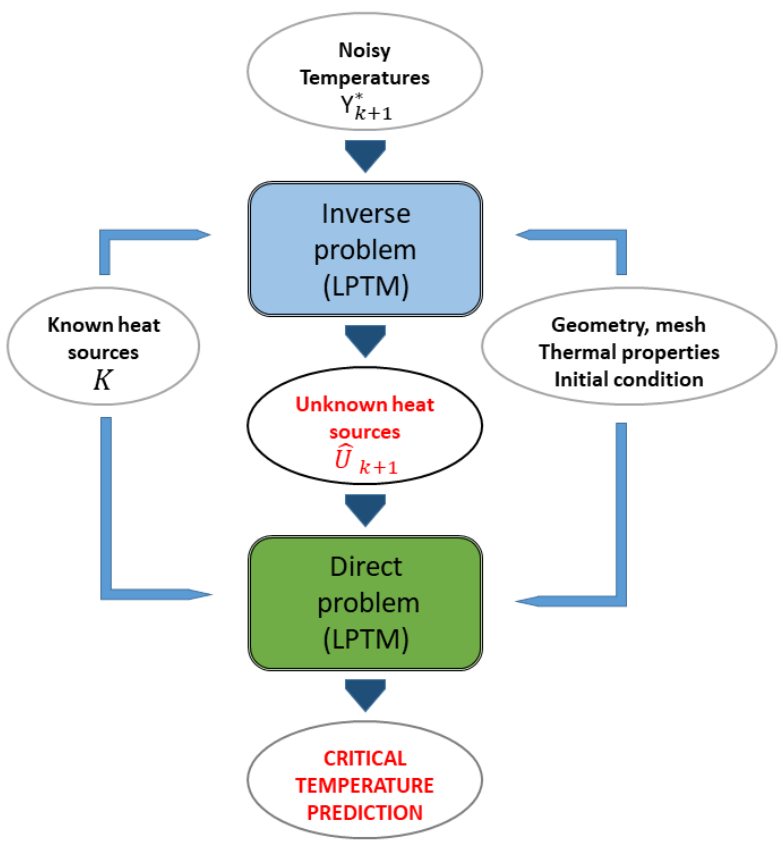

FIGURE 2. Block diagram: use of LPTM for both inverse and direct problems.

At each time-step, the model is solved in inverse problem to get motor losses. The inputs for inverse LPTM are the noisy temperature at accessible points (sensor temperature measurement on a real bench).

Then, forward LPTM is used to determine indicated critical temperatures.

\section{RESULTS AND ANALYSIS}

A scenario of motor operation is chosen corresponding to a profile mission in an aircraft flight application. The corresponding profiles of heat sources generated in the motor are depicted in Fig. 3 during $3600 \mathrm{~s}$. The different phases correspond to: taxi-out phase (0 to 450s), take off and climb (450 to 900s), cruise flight (900 to 2250s), descent and landing (2250s to 2700 s) and taxi-in (2700s to 3600 s).

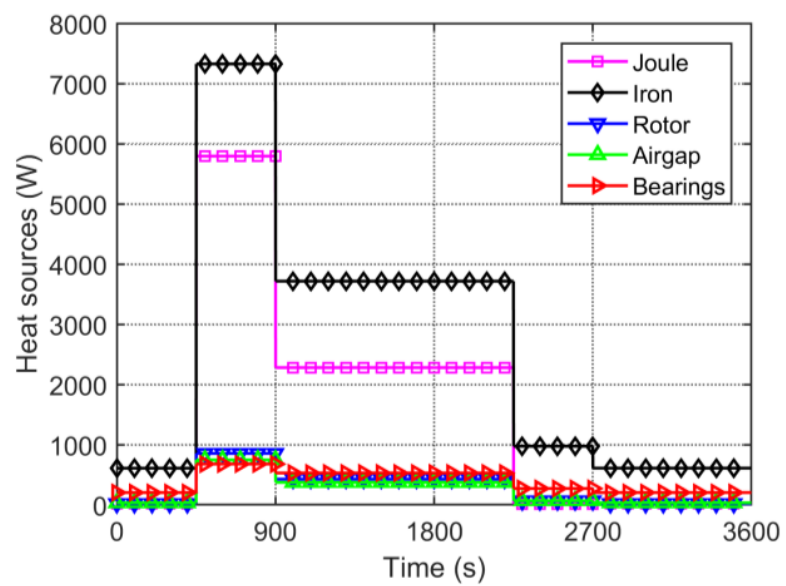

FIGURE 3. PMSM heat sources evolution as function of time PMSM. 
Rotor, Airgap, and Bearings losses remain relatively low and quite constant all along the mission whereas Joule and Iron losses change significantly. Those losses are particularly high during the take-off phase as they are linked to propulsion power. Airgap and Bearings losses depend principally on the rotor rotation speed, which varies slightly between take-off and cruise, and is very low during taxi phases.

Temperatures are then computed using LPTM and a time step equal to $1 \mathrm{~s}$. Among these temperatures, a set of observables is chosen depending on the different case studies (see subsection II.C). A noise of standard deviation equal to $\sigma=0.1^{\circ} \mathrm{C}$ is added to these observables so that they are used as temperature measurements in various inverse problems cases.

\section{A. CASE 1: IDENTIFICATION OF IRON LOSSES}

In this first case, among the five heat sources, four are supposed to be known $\left(P_{\text {Joule }} P_{\text {Rotor }} P_{\text {Airgap }} P_{\text {Bearings }}\right)$ and only iron losses $\left(P_{\text {Iron }}(t)\right)$ have to be identified. Fig. 4a shows the evolution of temperature Ts1 with respect to time. From this temperature, the inverse problem is solved in order to identify $P(t)=P_{\text {Iron }}(t)$ knowing $K(t)=\left[P_{\text {Joule }} P_{\text {Rotor }} P_{\text {Airgap }}\right.$ $\left.P_{\text {Bearings }}\right]^{T}$. Hence, for this case, $n_{q}=n_{U}=1$.

The procedure is sequential, as mentioned before, expressed in (14), and depends on the number of future time steps. Results of identification are presented in Fig. $4 \mathrm{~b}$ and Fig. $4 \mathrm{c}$ for respectively $n f=2$ and $n f=10$. It is remarkable that, without regularization $(n f=0)$, the oscillations of $P_{\text {Iron }}(t)$ are huge. Hence, we have chosen to draw $P_{\text {Iron }}(t)$ for $n f=2$ in Fig. 4 b.

It clearly appears that the number of future time steps filters the oscillations of $P_{\text {Iron }}$, what is confirmed by the quadratic criterion $\sigma_{U}$ in Table 1 . The main criterion, and the only one to be computed in a real case, is $\sigma_{Y}$. Its evolution with respect to $n f$ is quite interesting. For $n f=0$, even if the problem is ill-posed, large oscillations in $\widehat{U}$ allow to follow exactly the evolution of the noisy temperature. Hence, as indicated in Table $1, \sigma_{Y} \approx 0^{\circ} C$. When $n f$ increases, regularization tends to damp the time evolution of $\widehat{U}$, leading to a bias in the temperature computation. We choose then the number $n f$ for which $\sigma_{Y} \geq \sigma$ to "get out" of the noise level. The identification of $P_{\text {Iron }}(t)$ for $n f=10$ is depicted in Fig. 4c and shows a very good agreement with the exact evolution of these losses drawn in Fig. 3. 

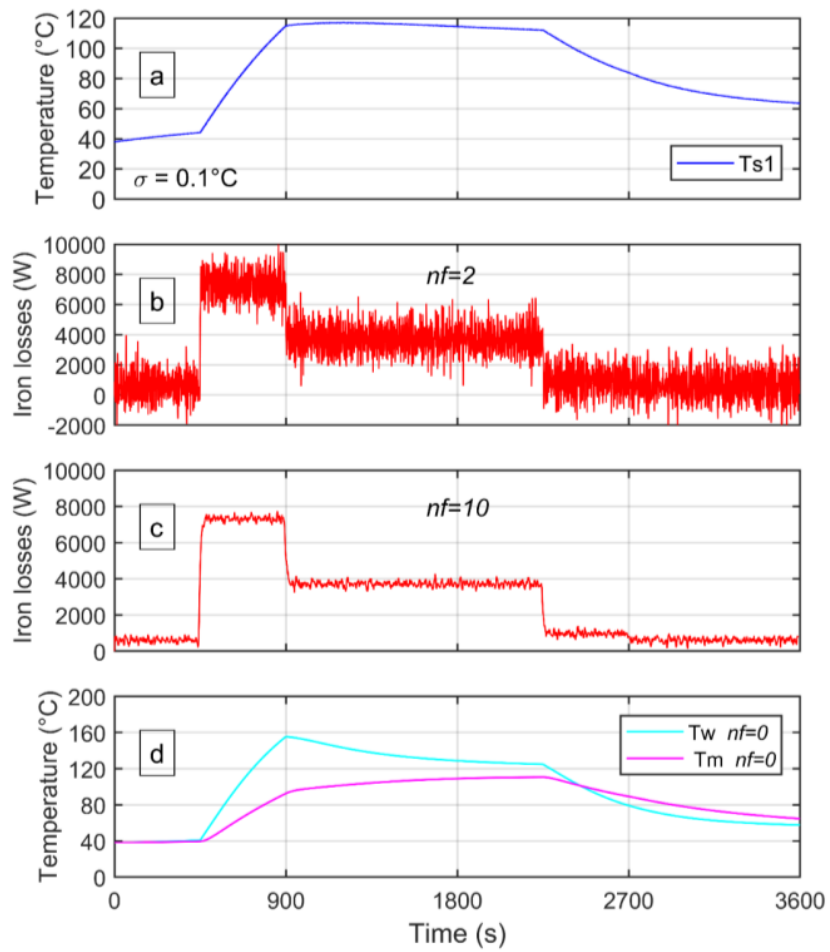

FIGURE 4. Iron losses identification from node Ts1 with $n f=2$ and $n f=10$ and computation of critical temperatures $\mathrm{Tw}$ and $\mathrm{Tm}$.

TABLE 1. Inversion results for iron losses identification from Ts1; bold lines correspond to results shown in Fig. 4.

\begin{tabular}{|c|c|c|}
\hline$n f$ & $\sigma_{U}(W)$ & $\sigma_{T S 1}\left({ }^{\circ} \mathrm{C}\right)$ \\
\hline 0 & 5303.1 & $3 \mathrm{e}-14$ \\
$\mathbf{2}$ & $\mathbf{9 3 6 . 7}$ & $\mathbf{0 . 0 8 7 1}$ \\
4 & 451.3 & 0.0935 \\
6 & 304.7 & 0.0964 \\
8 & 249.4 & 0.0988 \\
$\mathbf{1 0}$ & $\mathbf{2 2 9 . 2}$ & $\mathbf{0 . 1 0 0 9}$ \\
12 & 224.0 & 0.1034 \\
\hline
\end{tabular}

Once $P_{\text {Iron }}$ is identified, the aim is to predict temperatures $\mathrm{Tw}$ and $\mathrm{Tm}$ in inaccessible parts of the electric motor. They have been computed for the different values of $n f$ and are shown in Fig. $4 \mathrm{~d}$ for $n f=0$. Note that, for $n f=0$, temperature prediction occurs without any delay whereas it is executed with a 10 s delay with $n f=10$ since the time step $\Delta t$ is equal to $1 \mathrm{~s}$. For any value of $n f$, the temperature evolution in critical zones is the same, due to the fact that oscillations in $\widehat{U}$ are damped by the thermal path and inertia of the system. Same as in (15), critical temperatures Tw and $\mathrm{Tm}$ are compared to the exact temperatures computed with the exact inputs. For $n f=0$, a quadratic error $\sigma_{\text {Tcrit }}=0.003^{\circ} \mathrm{C}$ is obtained, which gives a very accurate prediction.

Now, a new test is carried out using a second measurement point Ts2 located in the stator. Graphical results are summarized in Fig. 5. 
It appears obviously that the oscillations of $P_{\text {Iron }}(t)$ decreased compared to Fig. 4, which is confirmed by Table 2 where $\sigma_{U}$ goes from $229 \mathrm{~W}$ to $200 \mathrm{~W}$ for $n f=10$. It is interesting to observe that in this case $\left(n_{q}=2, n_{U}=1\right)$ it is not possible to obtain $\sigma_{Y} \approx 0^{\circ} C$ for each of the two outputs from only one heat source $P_{\text {Iron }}(t)$.
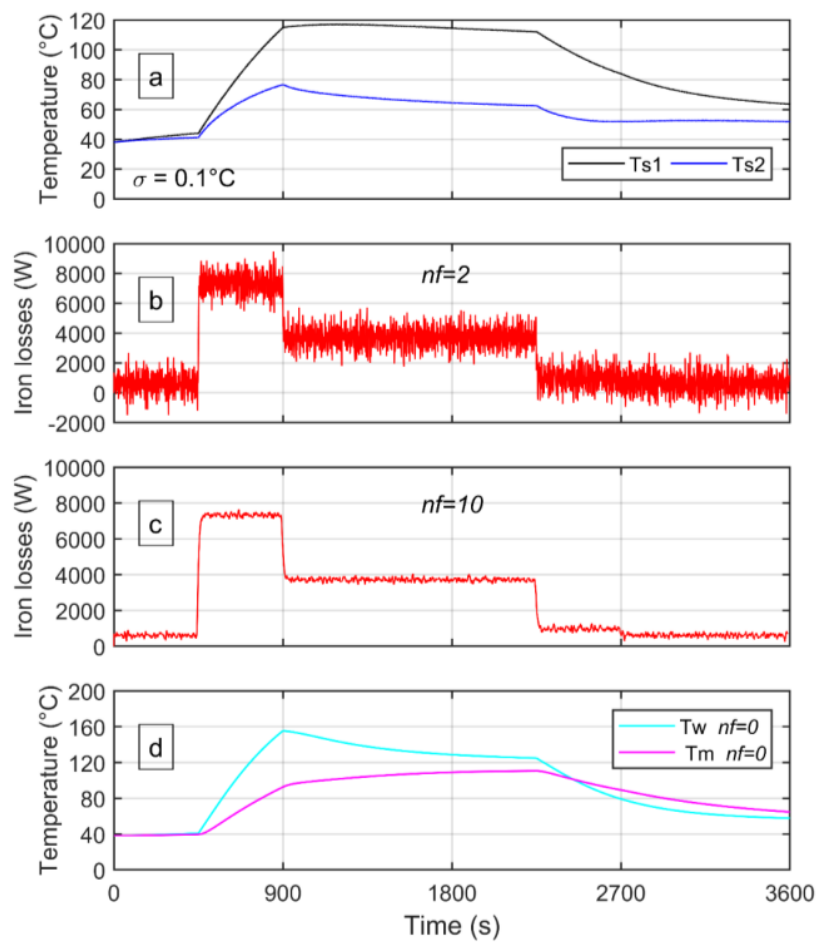

FIGURE 5. Iron losses identification from nodes Ts1 and Ts2 with $n f=2$ and $n f=10$ and computation of critical temperatures $\mathrm{Tw}$ and $\mathrm{Tm}$.

TABLE 2. Inversion results for iron losses identification from Ts1 and Ts2; bold lines correspond to results shown in Fig. 5.

\begin{tabular}{|c|c|c|c|}
\hline$n f$ & $\sigma_{U}(W)$ & $\sigma_{T s 1}\left({ }^{\circ} \mathrm{C}\right)$ & $\left.\sigma_{T s 2}{ }^{\circ} \mathrm{C}\right)$ \\
\hline 0 & 3713.2 & 0.0690 & 0.0700 \\
$\mathbf{2}$ & $\mathbf{6 7 3 . 8}$ & $\mathbf{0 . 0 9 2 1}$ & $\mathbf{0 . 0 9 2 9}$ \\
4 & 336.0 & 0.0957 & 0.0960 \\
6 & 237.5 & 0.0976 & 0.0975 \\
8 & 205.1 & 0.0992 & 0.0987 \\
$\mathbf{1 0}$ & $\mathbf{2 0 0 . 1}$ & $\mathbf{0 . 1 0 1 1}$ & $\mathbf{0 . 1 0 0 1}$ \\
12 & 205.0 & 0.1034 & 0.1020 \\
\hline
\end{tabular}

The temperature prediction in windings and magnets is also very accurate with an error $\sigma_{T c r i t}=0.002^{\circ} \mathrm{C}$ for $n f=0$. 


\section{B. CASE 2: IDENTIFICATION OF JOULE AND IRON LOSSES}

For the second case, Joule losses $\left(P_{\text {Joule }}\right)$ are also unknown. The evolutions of $P_{\text {Joule }}(t)$ and $P_{\text {Iron }}(t)$ have to be identified. Firstly, outputs Ts1 and Tsw located in the stator and at the winding surface are used. It can be remarked in Fig. 6 that both heat sources are well identified when increasing the number of future time steps. In this case, $n f=12$ gives $\sigma_{Y} \geq \sigma$ for each output, as shown in Table 3 .

The condition number of the matrix $S^{\mathrm{T}} \mathrm{S}$ to invert is also indicated. It is noteworthy that this last one decreases when the number of future time steps increases, which confirms the regularization effect of the function specification, knowing that in case $1, \mathrm{~S}^{\mathrm{T}} \mathrm{S}$ is a scalar, hence its condition number is equal to 1 .
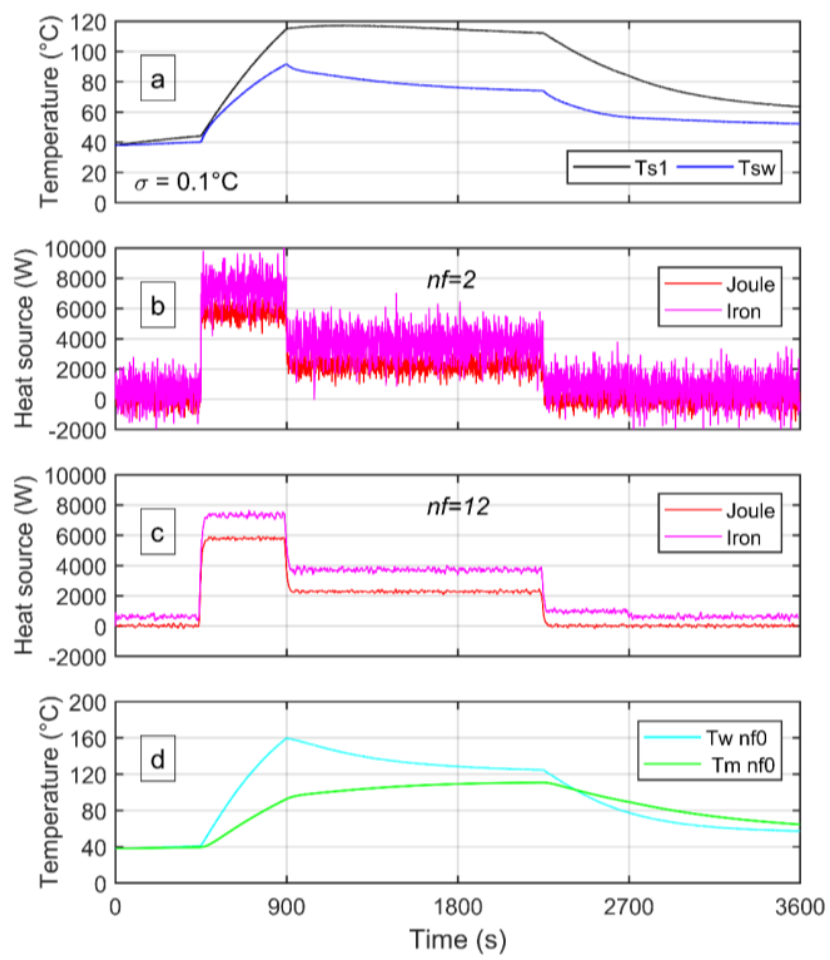

FIGURE 6. Joule and iron losses identification and computation of critical temperatures from nodes Ts1 and Tsw with $n f=2$ and $n f=12$.

Compared to case 1, the winding temperature is quite sensitive to the oscillations in Joule losses identification, hence the error increases: $\sigma_{T c r i t}=1.161^{\circ} \mathrm{C}$ for $n f=0$.

TABLE 3. Inversion results for Joule and iron losses identification from Ts1 and Tsw; bold lines correspond to results shown in Fig. 6.

\begin{tabular}{|c|c|c|c|c|}
\hline$n f$ & $\sigma_{U}(W)$ & $\sigma_{T S 1}\left({ }^{\circ} \mathrm{C}\right)$ & $\sigma_{T S W}\left({ }^{\circ} \mathrm{C}\right)$ & $C N\left(\mathrm{~S}^{\mathrm{T}} \mathrm{S}\right)$ \\
\hline 0 & 4125.2 & $3 \mathrm{e}-14$ & $6 \mathrm{e}-15$ & 3.74 \\
$\mathbf{2}$ & $\mathbf{7 4 1 . 2}$ & $\mathbf{0 . 0 8 5 9}$ & $\mathbf{0 . 0 8 6 9}$ & $\mathbf{3 . 6 4}$ \\
4 & 359.2 & 0.0926 & 0.0931 & 3.54 \\
6 & 246.4 & 0.0949 & 0.0971 & 3.45 \\
8 & 209.3 & 0.0970 & 0.1007 & 3.36 \\
\hline
\end{tabular}




\begin{tabular}{|l|l|l|l|l|}
\hline 10 & 198.9 & 0.0992 & 0.1051 & 3.28 \\
$\mathbf{1 2}$ & $\mathbf{2 0 0 . 4}$ & $\mathbf{0 . 1 0 1 7}$ & $\mathbf{0 . 1 1 0 4}$ & $\mathbf{3 . 2 0}$ \\
14 & 207.9 & 0.1047 & 0.1168 & 3.12 \\
\hline
\end{tabular}

In the other hand, by adding two other outputs Ts2 and Ts3, located in the stator, better inversion results are again obtained, as depicted in Fig. 7 and Table 4, since $\sigma_{U}$ goes from $200 \mathrm{~W}$ to $180 \mathrm{~W}$.
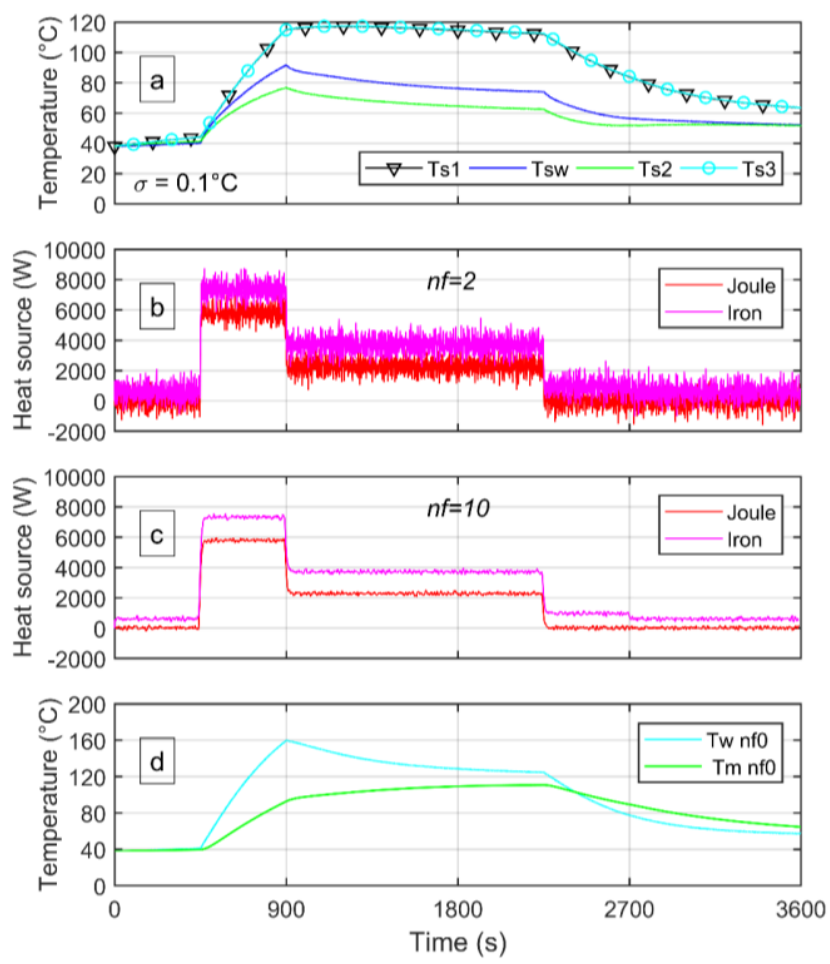

FIGURE 7. Joule and iron losses identification and computation of critical temperatures from nodes Ts1, Tsw, Ts2 and Ts3 with $n f=2$ and $n f=10$.

The addition of outputs acts as a filter in the inversion procedure and the condition number of matrix $\mathrm{S}^{\mathrm{T}} \mathrm{S}$ decreases also. The temperature prediction in windings and the magnets remains relatively accurate with an error $\sigma_{\text {Tcrit }}=1.158^{\circ} \mathrm{C}$ for $n f=0$.

TABLE 4. Inversion results for Joule and iron losses identification from Ts1, Tsw, Ts2 and Ts3; bold lines correspond to results shown in Fig. 7.

\begin{tabular}{|c|c|c|c|c|c|c|}
\hline$n f$ & $\sigma_{U}(W)$ & $\sigma_{T S 1}\left({ }^{\circ} \mathrm{C}\right)$ & $\sigma_{T S w}\left({ }^{\circ} \mathrm{C}\right)$ & $\sigma_{T s 2}\left({ }^{\circ} \mathrm{C}\right)$ & $\sigma_{T S 3}\left({ }^{\circ} \mathrm{C}\right)$ & $C N\left(\mathrm{~S}^{\mathrm{T}} \mathrm{S}\right)$ \\
\hline 0 & 2849.0 & 0.0803 & $3 \mathrm{e}-5$ & 0.0832 & 0.0816 & 1.26 \\
$\mathbf{2}$ & $\mathbf{5 1 8 . 4}$ & $\mathbf{0 . 0 9 4 1}$ & $\mathbf{0 . 0 8 6 7}$ & $\mathbf{0 . 0 9 7 4}$ & $\mathbf{0 . 0 9 5 2}$ & $\mathbf{1 . 2 3}$ \\
4 & 262.6 & 0.0964 & 0.0937 & 0.0994 & 0.0974 & 1.21 \\
6 & 194.5 & 0.0976 & 0.0975 & 0.1004 & 0.0987 & 1.18 \\
8 & 179.2 & 0.0990 & 0.1012 & 0.1012 & 0.0999 & 1.16 \\
$\mathbf{1 0}$ & $\mathbf{1 8 0 . 3}$ & $\mathbf{0 . 1 0 0 7}$ & $\mathbf{0 . 1 0 5 5}$ & $\mathbf{0 . 1 0 2 5}$ & $\mathbf{0 . 1 0 1 6}$ & $\mathbf{1 . 1 3}$ \\
12 & 188.3 & 0.1028 & 0.1109 & 0.1040 & 0.1038 & 1.11 \\
\hline
\end{tabular}




\section{CASE 3: IDENTIFICATION OF ALL LOSSES}

In this third case, the five heat sources altogether are considered unknown and have to be identified simultaneously from five outputs Ts1, Tc, Tsw, Ta and Tb, whose temperature evolutions are given in Fig. 8a.

These nodes are located in the stator, in the cavity, on the surface of the windings, in the air-gap and on the bearings respectively.
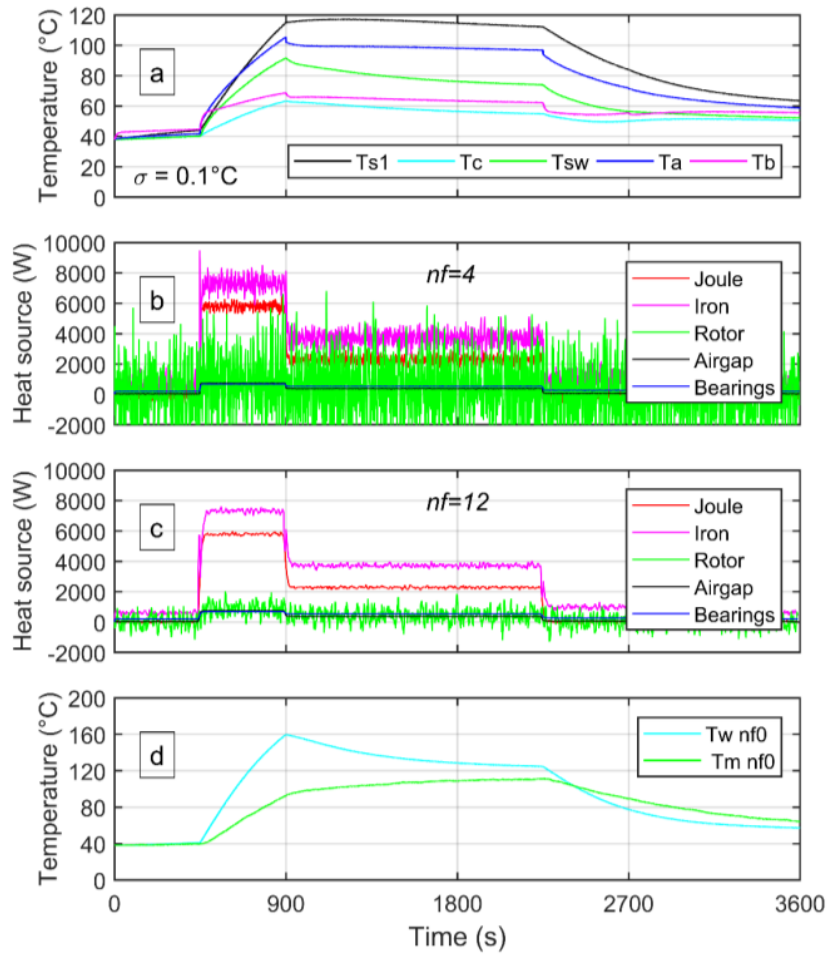

FIGURE 8. Identification of all the heat sources and computation of critical temperatures from nodes Ts1, Tc, Tsw, Ta and Tb with $n f=4$ and $n f=12$.

TABLE 5. Inversion results for all losses identification from Ts1, Tc, Tsw, Ta and Tb; bold lines correspond to results shown in Fig. 8.

\begin{tabular}{|c|c|c|c|c|c|c|c|}
\hline$n f$ & $\sigma_{U}(W)$ & $\sigma_{T s 1}\left({ }^{\circ} \mathrm{C}\right)$ & $\sigma_{T C}\left({ }^{\circ} \mathrm{C}\right)$ & $\sigma_{T S W}\left({ }^{\circ} \mathrm{C}\right)$ & $\sigma_{T a}\left({ }^{\circ} \mathrm{C}\right)$ & $\sigma_{T b}\left({ }^{\circ} \mathrm{C}\right)$ & $C N\left(\mathrm{~S}^{\mathrm{T}} \mathrm{S}\right)$ \\
\hline 0 & 11990.5 & $3 \mathrm{e}-14$ & $1 \mathrm{e}-14$ & $6 \mathrm{e}-15$ & $2 \mathrm{e}-14$ & $2 \mathrm{e}-14$ & $2.46 \mathrm{e} 6$ \\
2 & 1859.6 & 0.0881 & 0.0861 & 0.0842 & 0.1213 & 0.0876 & $4.48 \mathrm{e} 5$ \\
$\mathbf{4}$ & $\mathbf{8 5 9 . 3}$ & $\mathbf{0 . 0 9 7 3}$ & $\mathbf{0 . 0 9 3 0}$ & $\mathbf{0 . 0 9 1 3}$ & $\mathbf{0 . 1 6 3 9}$ & $\mathbf{0 . 0 9 9 6}$ & $\mathbf{1 . 8 2 e 5}$ \\
6 & 529.7 & 0.1038 & 0.0959 & 0.0952 & 0.1982 & 0.1129 & $9.90 \mathrm{e} 4$ \\
8 & 382.1 & 0.1100 & 0.0975 & 0.0990 & 0.2282 & 0.1295 & $6.23 \mathrm{e} 4$ \\
10 & 305.8 & 0.1169 & 0.0987 & 0.1037 & 0.2557 & 0.1490 & $4.85 \mathrm{e} 4$ \\
$\mathbf{1 2}$ & $\mathbf{2 6 3 . 9}$ & $\mathbf{0 . 1 2 4 3}$ & $\mathbf{0 . 1 0 0 0}$ & $\mathbf{0 . 1 0 9 6}$ & $\mathbf{0 . 2 8 1 6}$ & $\mathbf{0 . 1 7 1 2}$ & $\mathbf{4 . 2 9 e 4}$ \\
14 & 240.1 & 0.1326 & 0.1014 & 0.1167 & 0.3061 & 0.1950 & $3.82 \mathrm{e} 4$ \\
\hline
\end{tabular}


It can be remarked that the temperature magnitude is very different according to the outputs locations.

As for previous cases, the quadratic errors and the condition number are given with respect to the number of future time steps. In this case, the condition number of the matrix $S^{\mathrm{T}} \mathrm{S}$ is very high, hence, the noise in temperature measurements may be greatly amplified by the inverse problem. As in previous cases, $n f=0$ corresponds to a square case $\left(n_{q}=n_{U}=5\right)$, thus, even if the problem is ill-posed, large oscillations in $\widehat{U}$ allow to follow exactly the noisy temperature evolutions. Hence, as indicated in Table $5, \sigma_{Y} \approx 0^{\circ} C$. An increase of $n f$ leads to $\sigma_{Y} \geq \sigma$ for all outputs for $n f=12$. Fig. $8 \mathrm{c}$ shows large oscillations in $P_{\text {Rotor }}$ due to the fact that the outputs are located far from this heat source.

Concerning now the temperature prediction in windings and magnets (Fig. 8d), the error is completely acceptable with $\sigma_{T c r i t}=1.178^{\circ} \mathrm{C}$ for $n f=0$.

\section{CONCLUSION}

The study presented in this paper deals with the determination of electric motors' losses or heat sources, and prediction of critical temperature at non-accessible parts. A low-order lumped parameter thermal model is used to solve both inverse and direct problems. The method is sequential and includes regularization with the function specification technique. Different configurations are tested according to the number of heat sources to be identified. For each case, the influence of the required number of outputs to be used to solve the inverse problem and the number of future time steps are analyzed. The technique gives accurate prediction of the temperature in unreachable critical parts of the motor and is computationally efficient: only $10^{-3} \mathrm{~s}$ at each time step is needed for identification of the heat sources and prediction of the motor temperatures.

\section{REFERENCES}

1. Bilgin B, Magne P, Malysz P, Yang Y, Pantelic V, Preindl M, et al. Making the Case for Electrified Transportation. IEEE Trans Transp Electrification. 2015 Jun;1(1):4-17.

2. de Santiago J, Bernhoff H, Ekergård B, Eriksson S, Ferhatovic S, Waters R, et al. Electrical Motor Drivelines in Commercial All-Electric Vehicles: A Review. IEEE Trans Veh Technol. 2012 Feb;61(2):475-84.

3. Siemens. Electric propulsion components with high power densities for aviation. Transformative Vertical Flight Workshop; 2015 Mar 8.

4. ZUNUM Aero - JetBlue Technology Ventures [Internet]. Available from: https://www.jetblueventures.com/portfolio/zunum-aero/

5. Welstead J, Felder JL. Conceptual Design of a Single-Aisle Turboelectric Commercial Transport with Fuselage Boundary Layer Ingestion. In: 54th AIAA Aerospace Sciences Meeting [Internet]. San Diego, California, USA: American Institute of Aeronautics and Astronautics; 2016. Available from: http://arc.aiaa.org/doi/10.2514/6.2016-1027

6. E-Fan X [Internet]. Airbus. Available from: https://www.airbus.com/innovation/future-technology/electricflight/e-fan-X.html

7. Lefevre Y, El-Aabid S, Llibre J-F, Henaux C, Touhami S. Performance assessment tool based on loadability concepts. Int J Appl Electromagn Mech. 2019 Jan 1;59(2):687-94.

8. Popescu M, Staton DA, Boglietti A, Cavagnino A, Hawkins D, Goss J. Modern Heat Extraction Systems for Power Traction Machines-A Review. IEEE Trans Ind Appl. 2016 May;52(3):2167-75.

9. Nategh S, Boglietti A, Liu Y, Barber D, Brammer R, Lindberg D, Aglen O. A Review on Different Aspects of Traction Motor Design for Railway Applications. IEEE Trans Ind Appl. 2020 May;56(3):2148-57.

10. de Paula Machado Bazzo T, Kölzer JF, Carlson R, Wurtz F, Gerbaud L. Multiphysics Design Optimization of a Permanent Magnet Synchronous Generator. IEEE Trans Ind Electron. 2017 Dec;64(12):9815-23. 
11. Farsane K, Desevaux P, Panday PK. Experimental study of the cooling of a closed type electric motor. Appl Therm Eng. 2000 Oct 1;20(14):1321-34.

12. Woodbury KA. Inverse Engineering Handbook [Internet]. CRC Press; 2002. Available from: https://www.taylorfrancis.com/books/9780429117893

13. Khelifa M, Mordjaoui M, Medoued A. An inverse problem methodology for design and optimization of an interior permanent magnetic BLDC motor. Int J Hydrog Energy. 2017 Jul 13;42(28):17733-40.

14.Davin T, Pellé J, Harmand S, Yu R. Motor Cooling Modeling: An Inverse Method for the Identification of Convection Coefficients. J Therm Sci Eng Appl. 2017 Apr 25;9(4):041009-041009-13.

15. Vansompel H, Yarantseva A, Sergeant P, Crevecoeur G. An Inverse Thermal Modeling Approach for Thermal Parameter and Loss Identification in an Axial Flux Permanent Magnet Machine. IEEE Trans Ind Electron. 2019 Mar;66(3):1727-35.

16. Nair DG, Rasilo P, Arkkio A. Sensitivity Analysis of Inverse Thermal Modelling to Determine Power Losses in Electrical Machines. IEEE Trans Magn. 2018 Nov;54(11):1-5.

17. Nair DG, Arkkio A. Inverse Thermal Modeling to Determine Power Losses in Induction Motor. IEEE Trans Magn. 2017 Jun;53(6):1-4.

18. Marinova I, Mattev V. Inverse source problem for thermal fields. COMPEL - Int J Comput Math Electr Electron Eng. 2012; 31(3):996-1006.

19. Hey J, Malloy AC, Martinez-Botas R, Lamperth M. On-line monitoring of electromagnetic losses in an electric motor indirectly through temperature measurement. IEEE Trans Energy Conv. 2016 Dec; 31(4):134755 .

20. Huang C-H, Lo H-C. A three-dimensional inverse problem in estimating the internal heat flux of housing for high speed motors. Appl Therm Eng. 2006 Oct 1;26(14):1515-29.

21. Scott EP, Beck JV. Analysis of order of the sequential regularization solutions of inverse heat conduction problems. ASME J Heat Transfer 1989;111:218-224.

22. Osman AM, Dowding KJ, Beck JV. Numerical solution of the general two-dimensional inverse heat conduction problem. ASME J Heat Transfer 1997;119:38-45.

23. Touhami S, Lefevre Y, Llibre JF. Original Optimization Procedures of Halbach Permanent Magnet Segmented Array. In 19th International Symposium on Electromagnetic Fields in Mechatronics, Electrical and Electronic Engineering (ISEF), France; 2019.

24. Touhami S, Zeaiter A, Fénot M, Lefèvre Y, Llibre JF, Videcoq E. Electro-thermal Models and Design Approach for High Specific Power Electric Motor for Hybrid Aircraft. In Aerospace Europe Conference, Bordeaux, France, Feb. 2020, Accessed: Apr. 22, 2020. [Online]. Available: https://aerospaceeurope2020.eu/.

25. Gai Y, Kimiabeigi M, Chuan Chong Y, Widmer JD, Deng X, Popescu M, et al. Cooling of Automotive Traction Motors: Schemes, Examples, and Computation Methods. IEEE Trans Ind Electron. 2019 Mar;66(3):1681-92.

26. Tighe C, Gerada C, Pickering S. Assessment of cooling methods for increased power density in electrical machines. In: 2016 XXII International Conference on Electrical Machines (ICEM). 2016. p. 2626-32.

27. Nategh S, Barber D, Boglietti A, Lindberg D, Aglen O, Brammer R. A Study on Thermal Effects of Different Potting Strategies in Traction Motors. In: 2018 IEEE International Conference on Electrical Systems for Aircraft, Railway, Ship Propulsion and Road Vehicles \& International Transportation Electrification Conference (ESARS-ITEC) [Internet]. Nottingham: IEEE; 2018. p. 1-6. Available from: https://ieeexplore.ieee.org/document/8607600/

28. Zeaiter A, Fénot M. Thermal Sensitivity Analysis of a High Power Density Electric Motor for Aeronautical Application. In: 2018 IEEE International Conference on Electrical Systems for Aircraft, Railway, Ship 
Propulsion and Road Vehicles International Transportation Electrification Conference (ESARS-ITEC). 2018. p. $1-6$.

29. Beck JV, Blackwell B, St. Clair CR. Inverse heat conduction: ill-posed problems. New York: Wiley; 1985.

30. Videcoq E, Petit D, Piteau A. Experimental modelling and estimation of time varying thermal sources. Int J Therm Sci. 2003 Mar 1;42(3):255-65.

31. Beck JV, Blackwell B, Haji-Sheikh A. Comparison of some inverse heat conduction methods using experimental data. Int J Heat Mass Transf. 1996 Nov 1;39(17):3649-57.

32. Blanc G, Raynaud M, Chau TH. A guide for the use of the function specification method for $2 \mathrm{D}$ inverse heat conduction problems. Rev Générale Therm. 1998 Jan 1;37(1):17-30.

\section{Declarations}

This project has received funding from the European Union's Horizon 2020 (Cleansky 2 JTI) research and innovation program, 2014-2024 under grant agreement No 715483. 